IZA DP No. 5429

The Impact of Placing Adolescent Males into Foster Care on their Education, Income Assistance and Incarcerations

William P. Warburton

Rebecca N. Warburton

Arthur Sweetman

Clyde Hertzman

January 2011 


\title{
The Impact of Placing Adolescent Males into Foster Care on their Education, Income Assistance and Incarcerations
}

\author{
William P. Warburton \\ University of British Columbia
}

Rebecca N. Warburton

University of Victoria

Arthur Sweetman

McMaster University and IZA

Clyde Hertzman

University of British Columbia and CIAR

\author{
Discussion Paper No. 5429 \\ January 2011
}

IZA

P.O. Box 7240

53072 Bonn

Germany

Phone: +49-228-3894-0

Fax: +49-228-3894-180

E-mail: iza@iza.org

\begin{abstract}
Any opinions expressed here are those of the author(s) and not those of IZA. Research published in this series may include views on policy, but the institute itself takes no institutional policy positions.

The Institute for the Study of Labor (IZA) in Bonn is a local and virtual international research center and a place of communication between science, politics and business. IZA is an independent nonprofit organization supported by Deutsche Post Foundation. The center is associated with the University of Bonn and offers a stimulating research environment through its international network, workshops and conferences, data service, project support, research visits and doctoral program. IZA engages in (i) original and internationally competitive research in all fields of labor economics, (ii) development of policy concepts, and (iii) dissemination of research results and concepts to the interested public.
\end{abstract}

IZA Discussion Papers often represent preliminary work and are circulated to encourage discussion. Citation of such a paper should account for its provisional character. A revised version may be available directly from the author. 


\section{ABSTRACT \\ The Impact of Placing Adolescent Males into Foster Care on their Education, Income Assistance and Incarcerations}

Understanding the causal impacts of taking youth on the margins of risk into foster care is an element of the evidence-base on which policy development for this crucial function of government relies. Yet, there is little research looking at these causal impacts; neither is there much empirical work looking at long-term outcomes. This paper focuses on estimating the impact of placing 16 to 18 year old male youth into care on their rates of high school graduation, and post-majority income assistance receipt and incarceration. Two distinct sources of exogenous variation are used to generate instrumental variables, the estimates from which are interpreted in a heterogeneous treatment effects framework as local average treatment effects (LATEs). And, indeed, each source of exogenous variation is observed to estimate different parameters. While both instruments are in accord in that placement in foster care reduces (or delays) high school graduation, the impact of taking youth into care on income assistance use has dramatically different magnitudes across the two margins explored, and, perhaps surprisingly, one source of exogenous variation causes an increase, and the other a decrease, in the likelihood of the youth being incarcerated by age 20 . Our results suggest that it is not enough to ask whether more or fewer children should be taken into care; rather, which children are, and how they are, taken into care matter for long-term outcomes.

JEL Classification: J13, I13, I38

Keywords: foster care, local average treatment effects

Corresponding author:

Arthur Sweetman

Department of Economics

McMaster University

1280 Main St W.

Hamilton, ON, L8S 4L4

Canada

E-mail: Arthur.Sweetman@McMaster.ca

\footnotetext{
* This project was completed under the auspices of her honour Mary Ellen Turpel-Lafond, the Representative for Children and Youth for British Columbia. The authors thank the Michael Smith Foundation for Health Research for financial support. The views expressed in this paper are those of the authors and do not necessarily reflect the views of the Representative for Children and Youth, the Ministry for Children and Family Development, the government of BC or the MSFHR. The authors thank Heather Antecol, Jane Friesen, David Green, Thomas Lemieux, Louis-Philippe Morin, Craig Riddell, Jeff Smith, and seminar participants at SFU, UBC, McMaster, Dalhousie, Victoria, and the Canadian Economics Association annual meeting for helpful comments. Any errors are the responsibility of the authors.
} 
Protecting children and youth is a critical function of government and a major component of social programming in Canada. Allegations of abuse and neglect are investigated with the major and most extreme element of service provision being removing children from their homes and placing them in foster care. Although there are substantial fluctuations in levels across time, according to the HRSDC (2007) over 72,000 children and youth, or about $1 \%$ of the population, were in government care in Canada on March 31, 2004. ${ }^{1}$ (See also Canadian Peadiatrics Society, 2008.) Our estimate for the Canadian province of British Columbia (BC), the focus of our study, suggests that fully $5 \%$ of children will be in care at some point in their lives, and about $25 \%$ will have some contact with the relevant government Ministry. Younger children in care will generally be placed with foster families, but more than $10 \%$ of children in care are placed in group homes and this percentage is higher for older children and for male youth (Ryan et al. 2008; OACAS 2007).

Financial costs are another gauge of the magnitude and importance of a program, and the costs are substantial. In 2010 there were 8,960 children in foster care in BC. ${ }^{2}$ Gordon Hogg, then Minister of Children and Family Development, reported in 2001 that keeping a child in foster care cost roughly $\$ 40,000$ per year (McInnes, 2001). This implies that BC's total expenditure on foster care in 2010/2011 is more than $\$ 350$ million, which is more than the budget for 10 of BC’s 19 other Ministries (BC, 2010). ${ }^{3}$ This is not just a Canadian issue. In the United States, Scarcella et al. (2006) estimate total expenditure on child welfare services by national, state and local government at $\$ 23$ billion in fiscal year 2004, which dwarfs the budgets of Head Start, at $\$ 6.8$ billion (Head Start Bureau, 2006), and the Temporary

\footnotetext{
${ }^{1}$ Foster care levels within a jurisdiction can vary appreciably across relatively short time intervals as various policy changes come into effect. For example, in the US between 1999 and 2003 there was at least a 30\% increase in the number of children in care in Hawaii, West Virginia, Idaho, Wyoming and South Dakota while there was simultaneously at least a 30\% decrease in Illinois, Delaware and New York (AFCARS, 2006; US Bureau of the Census, 2007). Evidence of fluctuations in BC will be presented below. There appears to be no consistent and widespread view of the appropriate thresholds and/or proportions of children to take into foster care.

For a broad overview of child welfare issues see Kamerman, Phipps and Ben-Arieh (2010). Relatedly, income inequality among youth's households is seen to have a very large 'permanent' component by Burton and Phipps (2009), who observe considerable 'stickiness' in children's position in the income distribution.

${ }^{2}$ http://www.bcliberals.com/bc_liberal_record/children/\#protection

${ }^{3}$ Foster care expenditure is larger than the budgets of each of Labour; Small Business, Technology and Economic Development; Energy, Mines and Petroleum Resources; Aboriginal Relations and Reconciliation; Finance; Agriculture and Lands; Healthy Living and Sport; Tourism, Culture and the Arts; Environment; and Community and Rural Development.
} 
Assistance for Needy Families (TANF), at \$13 billion (McGuire and Merriman, 2006).

Despite the societal importance of foster care, and the substantial public resources devoted to it, we are aware of no research from an economic perspective using Canadian data. However, BC’s Representative for Children and Youth, and its Provincial Health Officer, (RCYBC and PHO, 2006, 2007, 2009) have undertaken an important empirical research program and have issued three joint special reports presenting novel and important descriptive analyses. Looking at health services utilization and mortality, educational experience, and youth justice experiences, these reports provide important input to the policy process and paint a statistical picture of a vulnerable population facing many challenges. They are the foundation stones of the current study. Although many quality services are currently provided to children and youth at risk, much more work is needed to better understand the child welfare system and its inter-connections with other areas of service delivery, and to provide evidence for ongoing evidencebased policy and program development. Outside of Canada, in contrast to programs such as Head Start or welfare/income assistance, relatively little economic research has been conducted, especially with respect to long-term outcomes, with the exception of Doyle (2007, 2008).

The policy question on which we focus is the causal impact on high school graduation, income assistance use and incarcerations of being taken into foster care for the marginal male youth who is at risk of coming into care. This paper is methodologically and substantively very similar to Doyle's (2007, 2008) work, but our data allow us to explore an aspect of heterogeneous treatment effects that was not possible given his data, but which is quite revealing. Although we focus on 16 to 18-year-old males in the empirical analysis (BC's age of majority is 19), the broad question is relevant to both sexes and all age groups, and we hope to extend the analysis in subsequent papers. Limiting the scope of the study to males who were 16 to 18 years old at the time of contact with the child protection system has three rationales. First, we suspect that the impact of being placed in care varies by age and sex, and so the results are easier to interpret for a more homogeneous group. Second, the policy change driving one of our instruments was particularly dramatic for this group, making that instrumental variable’s estimates stronger. Third, restricting the analysis to older children allows a sufficient follow-up period to permit measurement of 
outcomes after the children have reached the age of majority and left care.

In making the child removal decision there is a need to balance the risk of abuse and/or neglect in the home against the trauma of removal and the value of maintaining the family unit. Medium and longterm considerations regarding the value of alternative environments for each youth's ongoing development are also important factors. Given variation in risk from abuse and neglect across households, and in a context recognizing some degree of risk aversion with respect to each child's safety, the optimal rate of placement in care from the children's perspective would occur at the point where the risk-aversion adjusted expected marginal benefit resulting from placement in care just equals a similarly estimated marginal cost from the harm done as a result of separating the children from their parents. Unfortunately, there is almost no empirical information on the marginal costs and benefits of placement in government care, and it is the causal impacts of this that we seek to estimate.

The challenge in estimating the marginal costs and benefits arises from the selection process that results in the placement in care. Children and youth come to the attention of child protection agencies as a result of concern regarding abuse and/or neglect. Investigations are conducted by social workers and, where the concerns are substantiated, children are placed in care. ${ }^{4}$ Many investigators have compared the outcomes of children placed in care with other children; Eschelbach-Hansen (2006) provides a review drawing on American sources that is in accord with the three BC government reports discussed above. See also Berger and Waldfolgel (2004), and McDonald, Allen, Westerfelt, and Piliavin (1996). It is clear that outcomes are, on average, far worse for former children in care. However, differences in outcomes between former children in care and other children are likely attributable at least in part to the preceding abuse/neglect. Worse outcomes for children in care are not necessarily inconsistent with benefits from placement, those children's outcomes might have been worse still if they had not been placed in care.

Lawrence et al. (2006) do research that is closer to ours. They compare outcomes experienced by

${ }^{4}$ In BC, children may be removed under the authority of the Child, Family and Community Service Act. If the removal is done without a court order, the social worker must present in court within 7 days. While the decision to place a child in foster care is made by a judge, it is strongly influenced by the recommendation of the social worker. See e.g. Saunders and Goddard (1998 p. 30) who report, "Ultimately, decisions rest with workers." 
a group of children placed in foster care to those experienced by a group of children who were at risk of entering care, but "who remained with and were reared by caregivers who showed a continuous propensity for maltreating their children” (ibid, page 60). Pre-placement assessments using the Teacher Report Form (TRF) available for both groups provided a baseline measure of factors affecting adaptation and development. They found that "immediately following placement, children in foster care exhibited an increase in behaviour problems.” Although this suggests that foster care caused the increase in behaviour problems, the possibility that a traumatic event in the family or an egregious episode of abuse prompted both the placement in foster care and the behaviour problems cannot be ruled out.

To date the only research that makes a credible attempt to separate the effects of placement in care from the preceding conditions are the ground-breaking studies by Doyle $(2007,2008)$. He uses variation in the tendency of social workers to recommend that children be placed in care as an instrument to estimate the impact of placement in care on four important outcomes: delinquency/criminal activity, teen child bearing, employment and earnings. He finds that placing children in care between 1990 and 2001 decreases the likelihood that they will be employed in 2002 (not statistically significant in the IV estimates), reduces their earnings in 2002, increases the likelihood that they will become teen parents (statistically significant at the $10 \%$ level in the IV estimates) and increases the likelihood that they will be classified as delinquent. In his 2008 paper, he reports that children taken into care have two to three times greater arrest, conviction, and imprisonment rates than children who remained in their home.

Like Doyle’s papers, our analysis uses sources of quasi-randomization in an instrumental variables framework to separate the impact of placement in care from the impact of factors that led to placement in care. However, unlike Doyle we have access to two such sources: first, like him, we use caseworker administrative discretion as one source of variation; and second, we employ a one-time abrupt step up in the take-up rate driven by the findings of a judicial inquiry that was followed by a similar step down a few years later. Many papers in the program evaluation literature, such as Imbens and Wooldridge (2009), and Heckman, LaLonde, and Smith (1999), discuss the fact that in a heterogeneous treatment effect environment each instrument identifies a different treatment parameter, but few studies have two 
credible instruments that can be employed simultaneously in a common data set to explore this issue. We find that for some outcomes the two instruments provide similar coefficient estimates, but other outcomes appear to have quite different reactions on the two margins that we explore. Our results also provide the first estimates of the causal impact on educational attainment and use of the welfare system resulting from being taken into care. They also confirm, although only in part and with caveats, Doyle's results regarding contact with the criminal justice system. Interestingly, we observe very different impacts from our two sources for income assistance use and the incarceration rate; across-the-board changes seem much more problematic for long-term outcomes.

In the following section we describe the data. Next, we present the empirical strategy and then our results. Finally, we offer some conclusions and recommendations for future research.

\section{Data}

Linked and anonymized administrative records from the BC Ministries of Children and Family Development, Employment and Income Assistance, Education, and Public Safety and Solicitor General are employed. ${ }^{5}$ The sample for analysis derives from the set of investigations of allegations of abuse and neglect made to the Ministry of Children and Family Development, which is responsible for child welfare in BC. Monthly extracts of the Ministry’s information system from January 1993 to April 2003 form the backbone of this project. The opening or re-opening of a child protection file indicates that a child had come to the attention of the Ministry. The opening or re-opening of a child services file indicates that a child had been placed in care. ${ }^{6}$ In our analysis we used the first contact that resulted in a placement in

\footnotetext{
${ }^{5}$ Access to these data was obtained under the authority of the Representative for Children and Youth Act. All work was done on a secure machine in the controlled premises of the Representative for Children and Youth for BC; only aggregate data was released by the representative's office and only aggregate data were observed by the academic co-authors. Significant effort was put into preparing the data for analysis to ensure that the matching across the various data sources was appropriate and that the administrative data was appropriately "cleaned" for the analysis. We believe that the final data for analysis are reliable.

${ }^{6}$ This definition of placement in foster care is close to, but not identical to, the official Ministry definition. For the period for which we had access to official 'end of month' lists of children in foster care, we found that $85 \%$ of child services files that opened were in the list. An additional $4 \%$ had entered care during the month but were not on the official list because they had left care before the month end. The remaining $11 \%$ had a legal status that did not meet the official definition of being in care, but we view it as substantively similar.
} 
care, or, if the youth had not been placed in care, the first contact.

We received 26,334 records. We dropped: 789 observations for those who did not have a record in BC’s education system; 1,388 records where the individual had graduated from high school before contact; 1,962 records where we could not construct the worker fixed effect instrument (discussed below); 1,962 records where we could not construct the policy instrument; 6 observations that we could not link to a census subdivision; 395 observations where care started at age 16, but the break in care was less than a month; 9 observations relating to youth with special needs; 69 that could not be associated with a family; and 989 where contact occurred before May 1993. This left us with 20,727 observations of which 2,260 were subsequently placed in care.

In BC, income assistance (sometimes called welfare or social assistance) is provided to singles and childless couples as well as to one and two parent families. The Ministry of Employment and Income Assistance made available records of all income assistance recipients (whether the applicant was on the file as a spouse or child) by month from October 1990 to December 2005. We used these data to construct explanatory variables reflecting the income assistance paid to the youth/family before contact with the Ministry of Children and Family Development, and outcome variables for income assistance use after the youth turned 19.

The Corrections Branch of the BC Ministry of Public Safety and Solicitor General has maintained records of sentences handed down in BC since April 1, 1975. They provided us with an extract of the admissions and discharges from each institution in their data set. Individuals sentenced to federal institutions pass through provincial institutions so the records are complete.

\section{Institutional Context and Resulting Empirical Strategy}

In addition to taking advantage of the administrative data to generate a set of control variables, we seek to identify the causal impact(s) of being taken into care by exploiting the institutional context to locate source(s) of exogenous variation that permit the use of an instrumental variables estimator. Quite unusually, two credible instrumental variables are available to us. The first involves the discrete step up in 
the child apprehension rate that followed a judicial decision and a similarly discrete jump down just under three years later that resulted from an internal policy change. The second is akin to that employed by Doyle $(2007,2008)$ and follows from caseworkers exercising their administrative discretion as evidenced by the observation that there are appreciable differences in child apprehension rates across caseworkers despite children and youth being approximately randomly assigned to them.

Our first instrumental variable derives from a very unfortunate incident. In 1992 the murder by his mother of a four-year-old child who had not been taken into care led to a Judicial Inquiry into the child welfare system in BC by Judge Thomas Gove. The Inquiry held hearings in 1994 and 1995, and its recommendations, released in 1995, emphasized child protection. As a result, between 1995 and 1999, the number of children in care in BC increased from about 6,000 to about 10,000. If this increase had occurred as a result of increasing numbers of children contacted, we might expect the characteristics of the children to be correlated with the increase. However, Figure 1 shows that the number of contacts with the Ministry did not spike up in 1996, whereas the figure shows that the percentage investigations that ended up placing the youth in care did so. This is consistent with the formation of a new Ministry for Children and Families in 1996 to, in the then premier's words, "put our children and their safety first”. ${ }^{7}$ A few years later an internal review by the Ministry led to an equally abrupt reversal of the new policy, as can also be seen in Figure 1.

This instrument is operationalized as a series of indicator variables for the three different periods. Although our analysis focuses on the flow into care, to place this into context Figure 2 presents the stock of children and youth in care from 1979 to 2007. A long decline is evident at the start of our data period in January 1993, which is near the trough. This is followed by an abrupt increase in the stock (though not as abrupt as that to the flow) that reaches a maximum and then reduces to a plateau near the end of our data period in April 2003. Taking a longer perspective of the stock of those in foster care, and

\footnotetext{
${ }^{7}$ Quoted in a press release entitled "B.C. Child Protection System Overhauled”, issued by the BC Government Communications Office, September 23/1996. Accessed online at http://www2.news.gov.bc.ca/archive/pre2001/1996/0341.asp Accessed March 18, 2008. Discussions with people who had been Ministry employees at the time confirm explicit direction to take more children into care, backed up by high profile suspensions of social workers who did not.
} 
normalizing by the relevant population, the percentage in care peaked about 1970 at around $1.3 \%$ of the relevant population, and the trough was in 1993 when between 0.6 and $0.7 \%$ were in care.

We expect this first instrument to be valid because the mechanism for generating contacts, concerns regarding possible abuse and/or neglect expressed by neighbours, teachers, doctors, police, etc. did not change appreciably over the period in question - see Figure 1 for monthly counts of the number of contacts - but policies and practices regarding placing children in care did.

Administrative discretion among caseworkers is the source for the second instrument, and is conceptually identical to that employed by Doyle $(2007,2008)$ who discusses the justification at length. In short, two elements make it a credible instrumental variable. First, in an effort to ensure that caseworkers have roughly comparable workloads new investigations are effectively randomly assigned to them. For example, new investigations are rotated through caseworkers and/or the caseworker who is "on duty" during a certain period investigates new cases that arrive. As a result, the characteristics of new cases are not correlated with those of caseworkers.

Secondly, caseworkers -- Ministry employees, mostly trained social workers, who make recommendations regarding the children's placement in care -- have individual-level differences, which we refer to as fixed effects, in their propensities to take children into care. Moreover, we observe that these fixed effects can be substantial, as will be demonstrated below. The variability of attitudes towards placement in care across workers has long been recognized. Rossi et al. (1996) provide an interesting introduction to the literature on variability in worker decisions. While, as noted, the decision to place a child in care is ultimately made by a judge, it is strongly influenced by the recommendation of the social worker. Figure 3 presents the distribution of the percentage of cases investigated that result in a child coming into care, by caseworker-year, in our data period. Clearly there are massive differences across workers. Some of this follows from differences in the nature of the cases being investigated, and is affected by such factors as the demographics faced in each local office, but some reflects differences in the proclivity to take children and youth into care across caseworkers and it is this aspect of the variation that we exploit since cases are quasi-randomly assigned within offices. 
To operationalize the concept of a caseworker-fixed effect as an instrumental variable, we estimate the difference between each worker's propensity to place children in care in each year and that propensity for the other caseworkers in the same office and year. This approach addresses local area effects as well as trends over time. All contacts with the Ministry of Children and Family Development between January 1991 and April 2003, excluding the 16 to 18 year old males, are employed in these regressions. To ensure sufficient precision, only workers who had more than 10 contacts in the year are included in the sample, and the office that the worker was in had to have more than 10 additional contacts in the year. This provided 787,118 observations for use across a series of regressions, one per year, as depicted in equation (1).

$$
\text { InCare }=b_{0}+b_{1} \text { Office }+b_{2} \text { Month }+b_{3} \text { Age }+b_{4} \text { Female }+u
$$

In these ordinary least squares regressions a dummy variable indicating coming into care is regressed on a vector of dummy variables (with one category omitted for each) for each Office, each Month of the year, each year of Age, and for being Female. Even though the unit of observation in the regression is the child/youth, each residual $u$ is also associated with a particular caseworker, and that worker's annual fixed effect was calculated as the mean of the relevant error terms for that year. A plot of the distribution of worker fixed effects is depicted in Figure 4. Clearly, there is substantial variation across workers; the most extreme workers' probabilities of taking a youth into care differ by on the order of 30 or $40 \%$ from that of the average worker. As a test of the caseworker fixed effect instrument we explored regressions of the fixed effect on background/control variables and we do not see a significant relationship, which supports the contention that there is quasi-randomization.

The combination of quasi-random assignment of cases to caseworkers and caseworker-specific differences in the propensity to take children into care combine to provide a very credible instrumental variable; however in the heterogeneous treatment effect context where a Local Average Treatment Effect (LATE; Angrist and Imbens, 1994) is being estimated an additional assumption, frequently referred to as monotonicity, is also required. Angrist, Imbens and Rubin (1996) discuss the situation when monotonicity only holds approximately. This assumption rules out what are termed "defiers", that is, for example, youth 
who would have a reduced probability of being taken into care by virtue of being assigned to a caseworker with a high propensity to take youth into care. Given the nature of both of our instruments, it appears credible that this condition is substantively met in both cases.

\section{Descriptive Statistics}

Rates of high school graduation, welfare use, and sentencing, all vary systematically over the study period; plots of the trends for each by month for those at risk of coming into care are presented in Figures 5, 6 and 7 respectively. Our indicator of the high school graduation rate is the percent of students who had graduated by the end of the year in which they turned 19 (i.e., before their $20^{\text {th }}$ birthday), which is over one year longer than the age of the modal student who graduates part-way through their eighteenth year. Recall that some individuals may complete high school beyond age 20. This measure increased from $68 \%$ to $74 \%$ over the period of study. Income assistance, however, experienced even larger changes as part of a province-wide trend. The percentage of the entire population receiving income assistance increased from $9.7 \%$ in 1993 to a peak of $10.4 \%$ in 1995 and fell to $4.1 \%$ in 2002. ${ }^{8}$ In Figure 6 we show the percentage of those, according to the month that the investigation was initiated, who had any income assistance use in the year during in which they were age 19. Looking next at the number of individuals aged 19 to 25 starting a sentence in BC, it increased by 21\% between 1993 and 1996 and fell again by 7\% by 2003 in the general population. In Figure 7 we depict the incarceration rate for those investigated in a manner similar to that in Figures 5 and 6. A downward trend is evident. Seasonal effects are also present, and can be informally observed in Figures 5, 6 and 7.

Recognizing these background trends/patterns is a potentially important aspect of the analysis and our goal is to control for them in a very flexible way so that the instrumental variable estimates are credible and cannot be posited to result from spurious correlations on these dimensions. Therefore, as will

\footnotetext{
${ }^{8}$ BC Progress Board. Third Annual BC Progress Board Benchmarking Report Volume II - Internal Performance Review: Regional December 18, 2003 Appendix D RPI17 - SI: Percent of Population 0 - 64 years Receiving Basic BC Benefits (Income Assistance) Accessed online at http://www.bcprogressboard.com/2003Report/V2App.pdf March 18, 2008
} 
be shown below, we include a third order polynomial time trend and a set of month indicators. As an alternative to the polynomial trend, we experimented with using a series of year dummy variables for the worker fixed effect and, despite our concern, found that it made little substantive difference. In fact, our experiments with alternative specifications (not presented) found that the results were quite robust.

Descriptive statistics for the key variables are presented in Table 1. As can be seen in the top row, roughly $10 \%$ of investigations result in a child being removed, with the Gove Inquiry causing an almost $40 \%$ increase in the child apprehension rate (or just under 4 percentage points on the base of $10 \%$ ) in period 2. For the three dependent variables in our analysis - high school graduation by age 20, income assistance in the 12 months when the person was age 19, and the probability of being incarcerated when age 19 - two common patterns are evident. First, outcomes that are commonly judged to be poorer (lower probabilities of high school graduation and higher probabilities of income assistance receipt and incarceration) are observed for those taken into care. Of course, while some of these gaps may reflect the removal itself, they probably primarily reflect the underlying cause for the removal. Second, across the three periods of our data the trends discussed above are evident.

Descriptive statistics, by period, for the background variables employed are presented in Appendix Table 1.The most striking demographic characteristic of our sample is the percentage with selfdeclared Aboriginal heritage -- about 20\% compared with about 8\% for the population as a whole (see RCYBC and PHO, 2007). Our sample also shows significant contact with the other social services. For example, it shows an average of more than 8 physician visits per person in the two years prior to contact with the child protection system. It is notable, however, that even in our sample, visits that resulted in a diagnosis related to child maltreatment were very rare. The sample also had significant contact with Corrections before contact with the child protection system--about one in six of our sample had such contact. And, on average our sample received just under 6 months of benefits from the income assistance system in the two years prior to contact.

\section{Instrumental Variables Estimates}


Linear probability models are employed since we are not interested in fitted values but in average marginal effects, which appear to be reasonably estimated by the linear approximation that is OLS (see, e.g., the discussion by Moffit, 1999). Also, we need be less worried about inconsistent estimates from heteroscedasticity and/or omitted variables compared to non-linear models such as logits or probits. Moreover, we do not have testing procedures for overidentification, weak instruments and the like that are as well developed and understood for nonlinear endogeneous models. All of these factors encourage us to employ simple two stage least squares models.

\section{V.1 Instrumental Variables - First Stage}

A series of alternative first stage regressions from two-stage least squares estimates are presented in Table 2. These first stage regressions are, of course, common to each of the three dependent variables under study and a variety are presented to explore alternative specifications and the stability of our results. All of the regressions have 11 month indicators to control for seasonality, and each has either a third order polynomial in time, or a set of year indicators (when the worker fixed effects, but not the period indicators, are employed as instruments) to control for trends. Additionally, some specifications include a set of 28 background variables that control for characteristics observable in the administrative data. The standard errors are heteroscedasticity consistent and clustered at the level of the 2865 local office-years to accord with the estimates of the worker fixed effects. Also presented are partial- $\mathrm{R}^{2} \mathrm{~s}$ for the instruments (as suggested by Bound, Jaeger and Baker, 1995), and the test statistic and p-value for an F-test of the joint significance of the instrumental variables. Staiger and Stock (1997), and Stock and Yogo (2005), provide evidence suggesting that an F-statistic of the instrumental variables in the first stage is a useful measure to ensure the analysis does not suffer from a weak instrument problem. In all cases the test statistics presented are well in excess of the rule of thumb minimum of 10, and are in excess of the critical values presented by Stock and Yogo. We also calculated the Anderson canonical correlation and CraggDonald test statistics for under identification/weak instruments, which always had p-values smaller than 0.000, but they are not robust to clustering and as a result are biased towards small p-values. 
Turning to the coefficient estimates, the first two columns of Table 2 use only the period indicators following from the judicial inquiry as instruments and show that there is a 5 to 6 percentage point increase in the child apprehension rate, on a base just under $10 \%$ as seen in Table 1, in period 2 relative to period 3; period 1 is somewhere in the middle. The coefficient on the period 1 indicator is on the margin of being statistically significant at the $10 \%$ level, with the p-value reducing very slightly when the background variables are introduced to the regression (from a p-value of 0.092 to 0.130 - both the coefficient estimate and standard error decrease very slightly when the background variables are added). Regressions 3 through 6 also explore the worker fixed effect instrumental variable effect on the endogenous right-hand side InCare variable. Interestingly, the F-statistic is much larger for the worker fixed effect than it is for the period indicators, as is the partial $\mathrm{R}^{2}$, suggesting that the worker fixed effect is the more powerful instrument. Overall, although there are small changes, none of the instrumental variables' coefficients are much affected by the introduction of the background variables, or any of the other control variables, which is consistent with the idea that the instruments are not correlated with observable characteristics supporting the maintained hypothesis of quasi-randomization that justifies instrumental variables approach.

When both instruments are employed together, in column 7 and 8 (with, and without, the background variables respectively), the coefficient estimates do not move appreciably compared to those in the earlier regressions; the instruments do not appear to be correlated with each other or with the control variables. Columns 9 and 10 introduce interactions between the instrumental variables as additional instruments. As can be seen, the F-statistic declines and formal tests (column 9: $F(2,2864)=0.25$, $p$-value $=0.7750$; column $10: F(2,2864)=0.25$, $p$-value $=0.7769)$ show that there is no statistically significant difference between the coefficients of the three period indicators interacted with the worker fixed effect (and this is confirmed by the trivial increase in the relevant $\mathrm{R}^{2} \mathrm{~s}$ for the regressions seen in the bottom row). Overall, we believe that the regression in column 8 is our preferred specification when both instruments are employed since the addition of instruments that lack additional predictive power can be deleterious. 


\section{V.2 Instrumental Variables - Second Stage Findings}

Table 3 presents the instrumental variable results when high school graduation by age 20 is the dependent variable. This has the same format as the two subsequent tables for, in turn, income assistance use and the incidence of incarceration. As a sensitivity test, columns 1 through 5 include controls for 28 background variables, whereas columns 6 through 10 do not. Including exogenous background/control variables normally reduces the residual variation improving the estimator's precision. As is common in the literature, we believe these to be the preferred estimates. The first of each set of five regressions (columns 1 and 6) is an ordinary least squares regression, and the next four are instrumental variables estimates employing different combinations of instruments for the endogenous right-hand side indicator variable InCare. Although we have evidence that the instruments are not weak, nevertheless in addition to the tstatistic (based on standard errors that are robust to heteroscedasticity and clustering) for each coefficient we also provide the Anderson-Ruben statistic for the statistical significance of the endogenous regressor that is robust to weak instruments, as well as to heteroscedasticity and clustering. Moreover, the SarganHansen J-statistic is employed when there are multiple instruments; it is an over identification test, or in the context of heterogeneous treatment effects a test for instrument heterogeneity. That is, it can be interpreted as a test of whether the LATE estimates from the different sets of instruments are equal.

In column 1, with controls for the various background variables, the OLS coefficient estimate for InCare indicates that those who come into care are 13 percentage points less likely to graduate from high school by age 20 than those who are investigated but not taken into care; the gap is 17 percentage points, as seen in column 6, when the control variables are not included, indicating that some of the crosssectional gap can be explained by the observable characteristics in the data. Using only the period indicators as instruments, the point estimates in both columns 2 and 7 grow more negative, but the standard errors of the instrumental variables estimates are substantial and the coefficients are not statistically different from either the ordinary least squares coefficient or zero at conventional levels, though there is a roughly $85 \%$ chance that the instrumental variables coefficient differs from zero. In 
these, as in the other pairs of regressions in this table, including the control variables makes only a very small difference to the coefficient estimates.

Using the worker fixed effect as an instrument on its own, in columns 3 and 8, the point estimate is more negative than that for OLS and the standard error is substantially smaller than for the period indicators. Both t-statistics are significant at the $10 \%$ level, which accords with the p-values on the Anderson-Rubin statistics. While the instrumental variables coefficient in, for example, equation 3 is not statistically different from that estimated by OLS, the interpretation is dramatically different. OLS provides the difference in the average outcome, conditional on the covariates, between those male youth taken into care and those who remain with their families. However, the instrumental variable coefficient should be interpreted as the causal impact of being taken into care on the marginal children affected by the instrument, in this case the discretion of the social workers.

When the period indicators and the worker fixed effects are simultaneously employed as instrumental variables, the point estimate is very similar to that for the worker fixed effect alone. However, the J-statistic cannot differentiate between the instrumental variables. The estimate of the standard error decreases slightly causing the p-value of the t-statistic to increase slightly. In contrast, with controls for the background variables the Anderson-Rubin test statistic has a larger p-value because the degrees of freedom adjustment from the increased number of instruments outweighs the numerical increase in the statistic, whereas without controls the p-value decreases slightly since the point estimate of the coefficient is slightly larger. We show the results for the interacted set of instruments in columns 5 and 10, but we do not focus on them since they are not our preferred specification as discussed with respect to the first stage regressions.

Overall, we believe that the evidence suggests that on the margin taking children into care has a causal impact to reduce the probability that they graduate from high school by age 20. Given the available data we are not able to discern if this is a permanent reduction in the high school graduation rate, a delay in high school graduation, or a combination of the two.

The OLS estimates in Table 4 suggest that being taken into care is associated with an increase in 
income assistance use in the year before turning 20. As with the results seen in Table 3, the regressions with control variables have slightly smaller point estimates and standard errors, but the basic pattern is similar with and without controlling for these background characteristics. Column 1 indicates that those taken into care receive approximately 1.6 additional months of income assistance. Column 2, employing only the period indicators, has a point estimate that is substantially and statistically significantly larger than that estimated by OLS, and it is statistically significant at the $1 \%$ level by both the t-statistic and the Anderson-Ruben test. When the worker fixed effect is employed on its own the point estimate is slightly smaller, but quite similar, to the OLS estimate. However, the standard errors are sufficiently large that the coefficient is not statistically significantly different from zero.

In columns 4 and 8, when both instruments are employed simultaneously, the point estimate is part way between those in the previous two instrumental variables regressions and the coefficient estimate is clearly statistically different from zero, but the J-statistic suggests that the sets of instruments are not providing estimates that are consistent with each other; informally, this can be interpreted as indicating that the point estimates in columns 2 and 3 (and 7 and 8) are statistically different from each other. It appears that the effect of the across-the-board increase in the child apprehension rate following the judicial inquiry had a substantially larger effect in causally increasing income assistance use following the age of majority for those taken into care as a result of the policy change. In contrast, while there is a causal impact on income assistance use among those youth taken into care by caseworkers with a higher propensity to take youth into care, the impact is much more modest. Although we can only speculate, the increase following the judicial inquiry "flooding" the number of foster care spots available and thereby reducing the quality of service provision, and/or the associated reduction of an aspect of caseworkers' discretion (i.e., the bluntness of across-the-board increases), may be behind this substantial increase of approximately 6 months of income assistance use in the year. It would appear that the LATE estimates for these two sources of exogenous variation are quite different, and that alternative approaches to generating variations in the probability of coming into care have different impacts on the margin.

Table 5 has a similar layout to the previous two tables, but the incidence of incarceration while 19 
years of age is the dependent variable. Columns 1 and 6, displaying the OLS output, indicates that those taken into care are a few percentage points more likely to be incarcerated than those not taken into care. Given that incarceration is a relatively rare event, as seen in Table 1, these differences are appreciable. In columns 2 and 7, using the indicators resulting from the jump in the incarceration rate as a result of the judicial inquiry, the point estimate is seen to be substantially larger than that for OLS. Interestingly, the point estimate is not statistically significant judged relative to the estimate's standard error and the resultant t-statistic, but the Anderson-Rubin statistic, which may be argued to have better statistical properties in this context, suggests that the instrumental variables point estimate is different from zero with p-values of about 4 and 7\%. Perhaps more surprisingly, the J-statistic suggests that the two period indicators provide different point estimates - the impacts of a step up, and step down in the child apprehension rates are not mirror images of each other. This makes some sense if, for example, one believes that the stock and quality of foster care placements is an important factor in the outcomes of youth taken into care. Following the step up the quality would deteriorate since the supply of potential foster care placement spots would take time to adjust, but the step down would be associated with an increase in quality (i.e., there would be less demand on the existing number of spots).

In dramatic contrast to the results just observed, when the worker fixed effect is employed on its own, the point estimate is negative as opposed to positive! Although it is not statistically significant at conventional levels, it is seen to be statistically significant at a level only slightly larger than $10 \%$ in the Anderson-Rubin test (especially in column 3), and the p-value on the coefficient's t-statistics is 0.129 in column 3 , and 0.189 in column 8 . This suggests that there is a substantial probability that the true coefficient estimate is below zero. Moreover, the column 3 point estimate does appear to be statistically significantly less than the OLS estimate, which might be a more important comparison than is zero.

When the two sources of exogenous variation are employed simultaneously, in columns 4 and 9, the point estimate is negative, and not statistically different from zero according to the t-statistic, but statistically significant according to the Anderson-Ruben test. Further, and as expected given the results to this point, the J-statistic suggests that the two instruments have statistically significantly different 
estimates. That is, the across-the-board changes in the child apprehension rate, and caseworker discretion, appear to have quite different impacts on incarceration rates later in life. While further work will be required to confirm these results, a plausible interpretation is that the across-the-board changes in the child apprehension rate subsequent to the judicial inquiry had a causal impact increasing the rate of incarceration for those taken into care as a result of the policy change. In stark contrast to this, the administrative discretion exercised by social workers appears to beneficially reduce the subsequent rate of incarceration for those taken into care by caseworkers with higher propensities to take children into care. This is a remarkable finding and a very strong illustration of the point that different sources of exogenous variations are estimating different LATE parameters.

\section{Conclusion}

We view this paper as only scratching the surface with respect to the potential for empirical research that could be of benefit to policymaking with respect to foster care. Clearly, the results found here apply only to 16, 17 and 18-year-old male youth, and it would be very interesting to undertake similar analyses for different demographic groups were the data made available. It would also be valuable to extend the analysis to other dependent variables, particularly those associated with health outcomes, and to look at related aspects of being taken into care, such as the duration away from the family.

Overall, the background research cited shows clearly that those taken into care have quite poor outcomes, but we are interested in more subtle effects - the causal impacts of being taken into care for those on the margin of being apprehended. We observe that the impact on some outcomes under study varies according to the source of exogenous variation used to identify the causal impact. Aside from the substantive findings, this is a useful example of heterogeneous treatment effects where alternative instrumental variables sweep out effects that are statistically different from each other - that is, they estimate different LATE parameters. In effect, there are different individuals on the margin of being taken into care, and/or they are treated differently by the process of being taken into and being in care, as a result of these two distinct sources of exogenous variation. 
These data suggest that high school graduation becomes less likely and/or delayed as a result of both sources of exogenous variation, that income assistance use increases dramatically more as a result of the across-the-board increase in the child apprehension rate, and that the causal impact on the probability of incarceration actually goes in two different directions as a result of the two different treatments. The across-the-board increase appears to causally increase incarceration rates, whereas, in the context of a relatively stable system, being taken into care by a caseworker who has a higher probability of taking youth into care appears to decrease incarceration rates for those affected children. Of course, the interpretation of these results needs more information. It might not be the act of being taken into care that is driving much of the observed difference; rather, it may follow from the ability of the foster care system to deal with a dramatic and sharp change in the number of children flowing into care, as opposed to the consistent flow resulting from a stable average child apprehension rate (even if caseworkers have diverse apprehension rates).

This is clearly an important area of study affecting many of the most vulnerable individuals in our population, and it also raises many very interesting technical/econometric challenges. It looks like an area in which much fruitful future work could be undertaken. 


\section{References}

Angrist, Joshua D., and Guido W. Imbens (1994) "Identification and Estimation of Local Average Treatment Effects,” Econometrica 62(2), 467-475

Angrist, Joshua D., Guido W. Imbens and Donald B. Rubin (1996) "Identification of causal effects using instrumental variables," Journal of the American Statistical Association 91(434), 444-55

AFCARS (2006). The AFCARS Report Preliminary FY 2005 Estimates as of September 2006 Accessed online. http://www.acf.hhs.gov/programs/cb/stats_research/afcars/tar/report13.htm Dec 26, 2006

Berger, Lawrence and Jane Waldfogel (2004) "Out-of-Home Placement of Children and Economic Factors: An Empirical Analysis,” Review of Economics of the Household 2(4), 387-411

BC (2010). Estimate: Fiscal Year Ending March 31, 2011 Accessed online. http://www.bcbudget.gov.bc.ca/2010/estimates/2010_Estimates.pdf January 3, 2011

Bound, J., D. Jaeger, and R. Baker (1995) "Problems of instrumental variable estimation when the correlation between the instruments and the endogenous explanatory variables is weak," Journal of the American Statistical Association 90, 443-50

Burton, Peter and Shelley Phipps (2009) The Prince and the Pauper: Movement of Children Up and Down the Canadian Income Distribution, 1994-2004. mimeo, Dept. of Economics, Dalhousie University

Canadian Paediatric Society (2008) "Special considerations for the health supervision of children and youth in foster care," Paediatrics \& Child Health 13(2), 129-32

Doyle, J.J. Jr. (2008) "Child Protection and Adult Crime: Using Investigator Assignment to Estimate Causal Effects of Foster Care," Journal of Political Economy 116(4), 746-70

Doyle, J.J. Jr. (2007) "Child Protection and Child Outcomes: Measuring the Effects of Foster Care," American Economic Review 97(5), 1583-1610

Eschelbach-Hansen Mary (2007) "The Value of Adoption," Adoption Quarterly 10(2), 65-87

Head Start Bureau (2006) Head Start Program Fact Sheet Fiscal Year 2006 Accessed online. http://www.acf.hhs.gov/programs/hsb/research/2006.htm December 26, 2006

Heckman, James, Robert LaLonde, and Jeffrey Smith (1999) "The Economics and Econometrics of Active Labor Market Programs,” in Handbook of Labor Economics, Vol 3A, eds. Orley Ashenfelter and David Card (Amsterdam: North-Holland), 1865-2097

HRSDC (2007) Child and Family Services Annual Statistical Report 2000-2001 to 2003-2004, HS254/2004E-PDF

Imbens, Guido W., and Jeffrey M. Wooldridge (2009) "Recent Developments in the Econometrics of Program Evaluation," Journal of Economic Literature 47(1), 5-86

Kamerman, Sheila, Shelley Phipps and Asher Ben-Arieh, eds. 2010 From Child Welfare to Child Wellbeing: An International Perspective on Knowledge in the Service of Making Policy. A special volume in honor of Alfred Kahn (Springer Press)

Lawrence, Catherine R., Elizabeth A. Carlson, and Byron Egeland (2006) "The impact of foster care on development," Development and Psychopathology 18, 57-76

McDonald, Thomas P., Reva I. Allen, Alex Westerfelt, and Irving Piliavin (1996) Assessing the LongTerm Effects of Foster Care: A Research Synthesis (Washington, D.C.: CWLA Press)

McGuire Therese J. and David Merriman (2006) "Has Welfare Reform Changed State Expenditure Patterns?” Policy Brief \#7 National Poverty Center. Accessed online. http://www.npc.umich.edu/publications/policy_briefs/brief7/ January 31, 2007.

McInnes, Craig (2001) Vancouver Sun, October 3, 2001

Moffit, R.A. (1999) "New Developments in Econometric Methods for Labor Market Analysis","” in Handbook of Labor Economics, Vol 3A, eds. Orley Ashenfelter and David Card (Amsterdam: North-Holland), 1368-94

OACAS (Ontario Association of Children's Aid Societies, 2007) More Foster Families Needed in Ontario, News Release October 21, 2007 Accessed online. http://www.oacas.org/newsroom/releases/newsreleasefosterfamily07oct21.pdf April 23, 2008 
RCYBC and PHO (2006). Health and Well-Being of Children in Care in BC: Report 1 on Health Services Utilization and Mortality. Accessed online. http://www.gov.bc.ca/cyo/popt/javascript_version/special_reports.htm February 5, 2007

RCYBC and PHO (2007) Health and Well-Being of Children in Care in B.C.: Educational Experience and Outcomes, Accessed online. http://www.rcybc.ca/Images/PDFs/Reports/educational\%20outcomes\%20of\%20cic.pdf

RCYBC and PHO (2009) Kids, Crime and Care: Youth Justice Experiences and Outcomes, Accessed online.

www.rcybc.ca/Images/PDFs/Reports/Youth\%20Justice\%20Joint\%20Rpt\%20FINAL\%20.pdf

Rossi, Peter H.; Schuerman, John R. and Budde, Stephen (1996) Understanding Child Maltreatment Decisions and Those Who Make Them (Chicago: Chapin Hall Center for Children at the University of Chicago)

Ryan, Joseph P.; Jane Marie Marshall, Denise Herz, Pedro M. Hernandez (2008) "Juvenile delinquency in child welfare: Investigating group home effects,” Children and Youth Services Review 30(9), 1088-99

Saunders, Bernadette and Chris Goddard (1998) A Critique of Structured Risk Assessment Procedures: Instruments of Abuse National Research Centre for the Prevention of Child Abuse, Caulfield East VIC Australia. Accessed online. childhood.org.au/downloads/A_critique_of\%20structured_risk_assessments.pdf Feb. 7, 2007

Scarcella, Cynthia Andrews; Roseana Bess; Erica Hecht Zielewski; Rob Geen (2006) The Cost of Protecting Vulnerable Children V: Understanding State Variation in Child Welfare Financing, The Urban Institute, Washington

Staiger, D., and J. H. Stock. (1997) "Instrumental variables regression with week instruments," Econometrica 65, 557-86

Stock, J. H., and M. Yogo. (2005) "Testing for weak instruments in linear IV regression," in Identification and inference for econometric models: essays in honor of Thomas Rothenberg, eds. D. W. K. Andrews and J. H. Stock (Cambridge: Cambridge University Press) 80-108

US Bureau of the Census (2007) Estimates of the Population by Selected Age Groups for the United States and States, and for Puerto Rico: July 1, 2006 (SC-EST2006-01) 


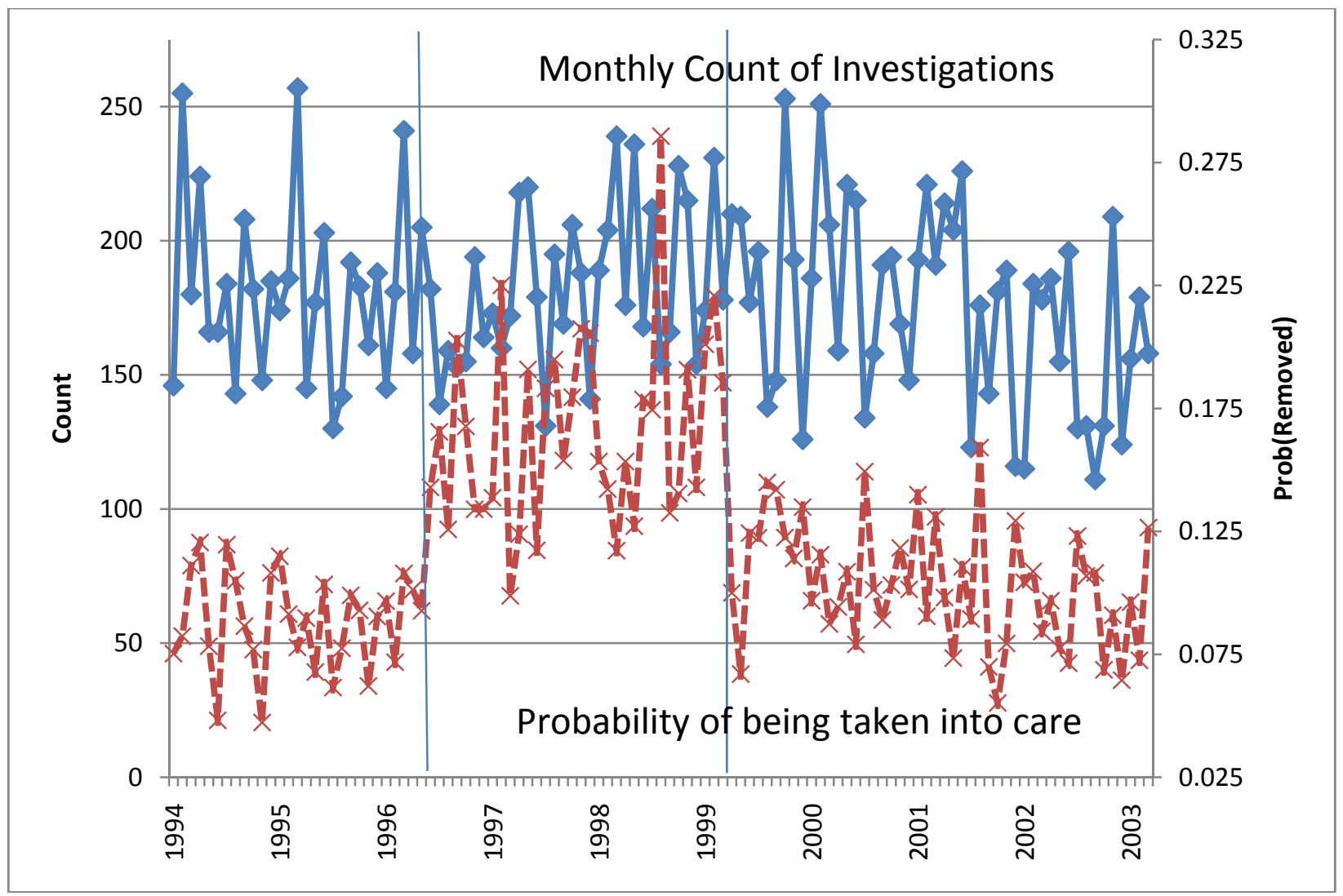

Figure 1 - Count of Youth at Risk and Probability of being Taken into Care 


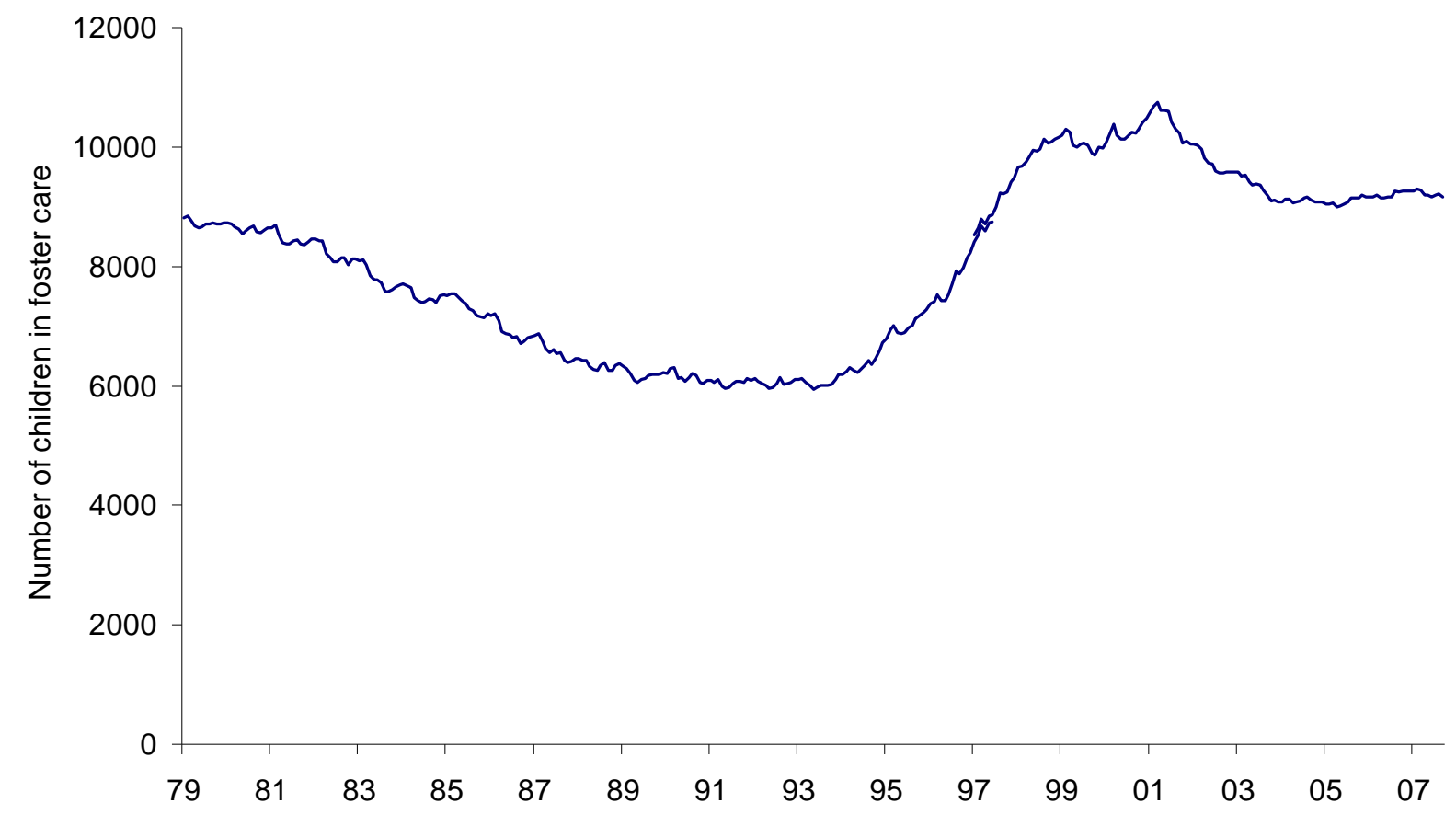

Figure 2 - Number of Children in Care in BC from 1979 to 2007 


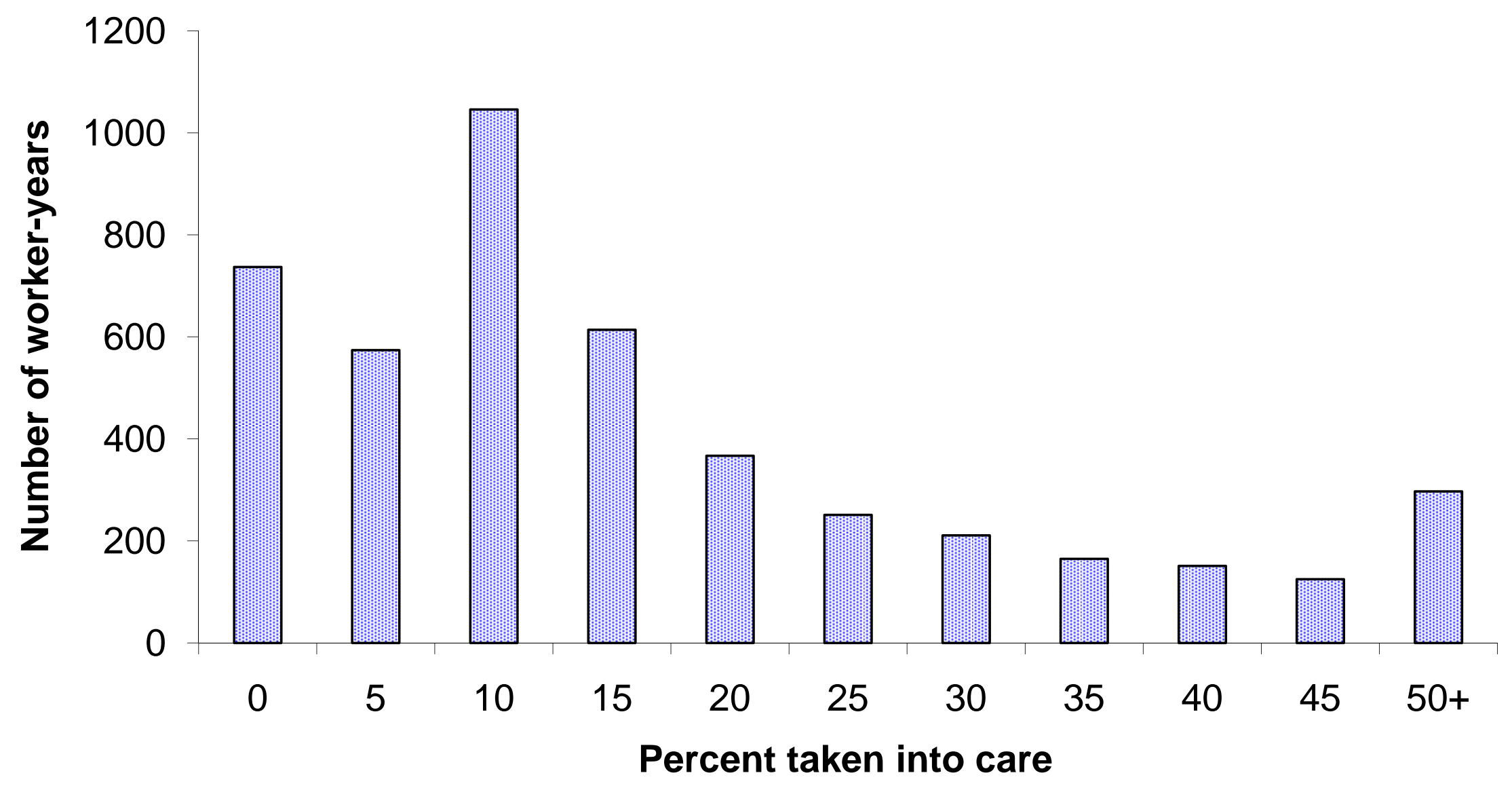

Figure 3 - Percent of Investigations Where Children are taken into Care by Caseworker 


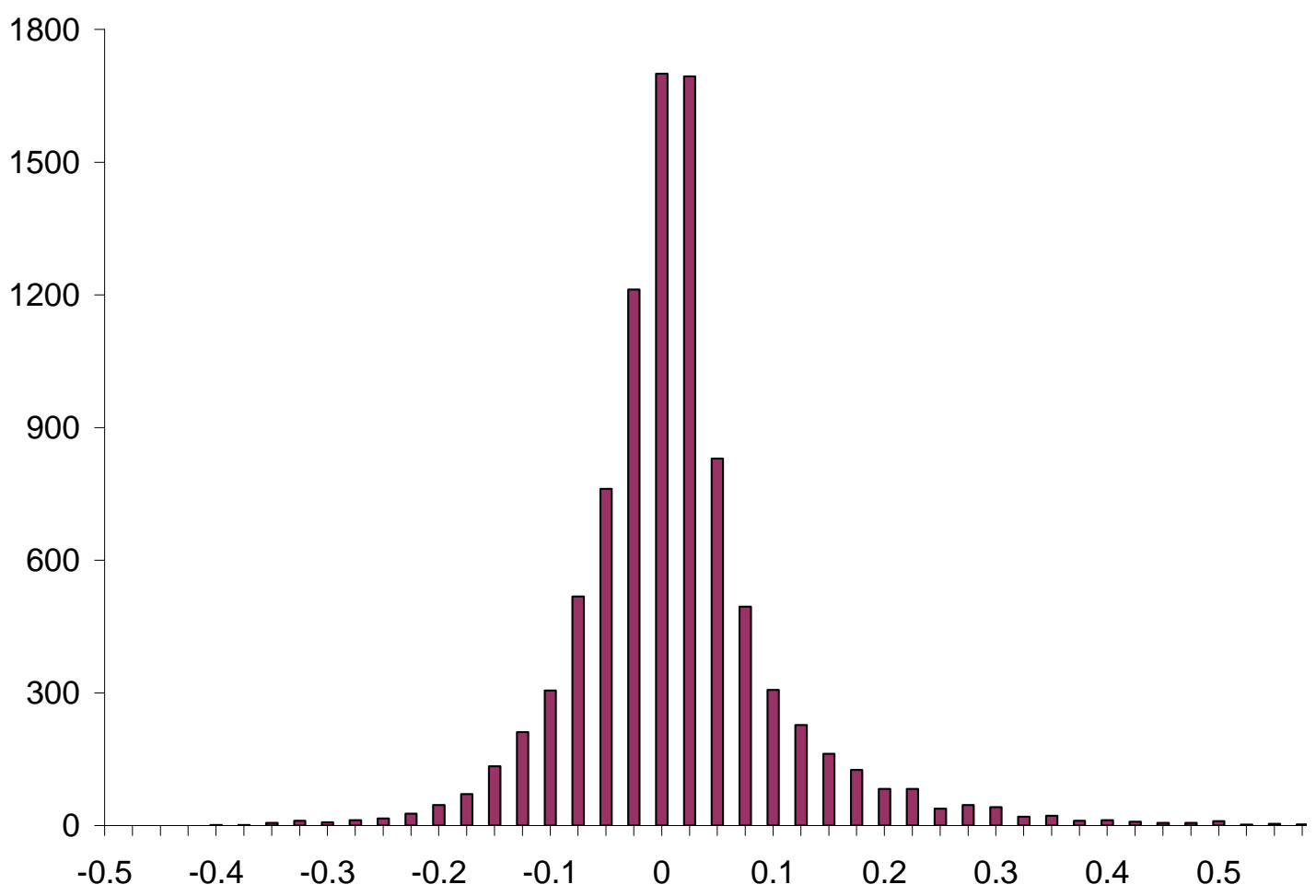

Figure 4 - Caseworker Fixed Effects 


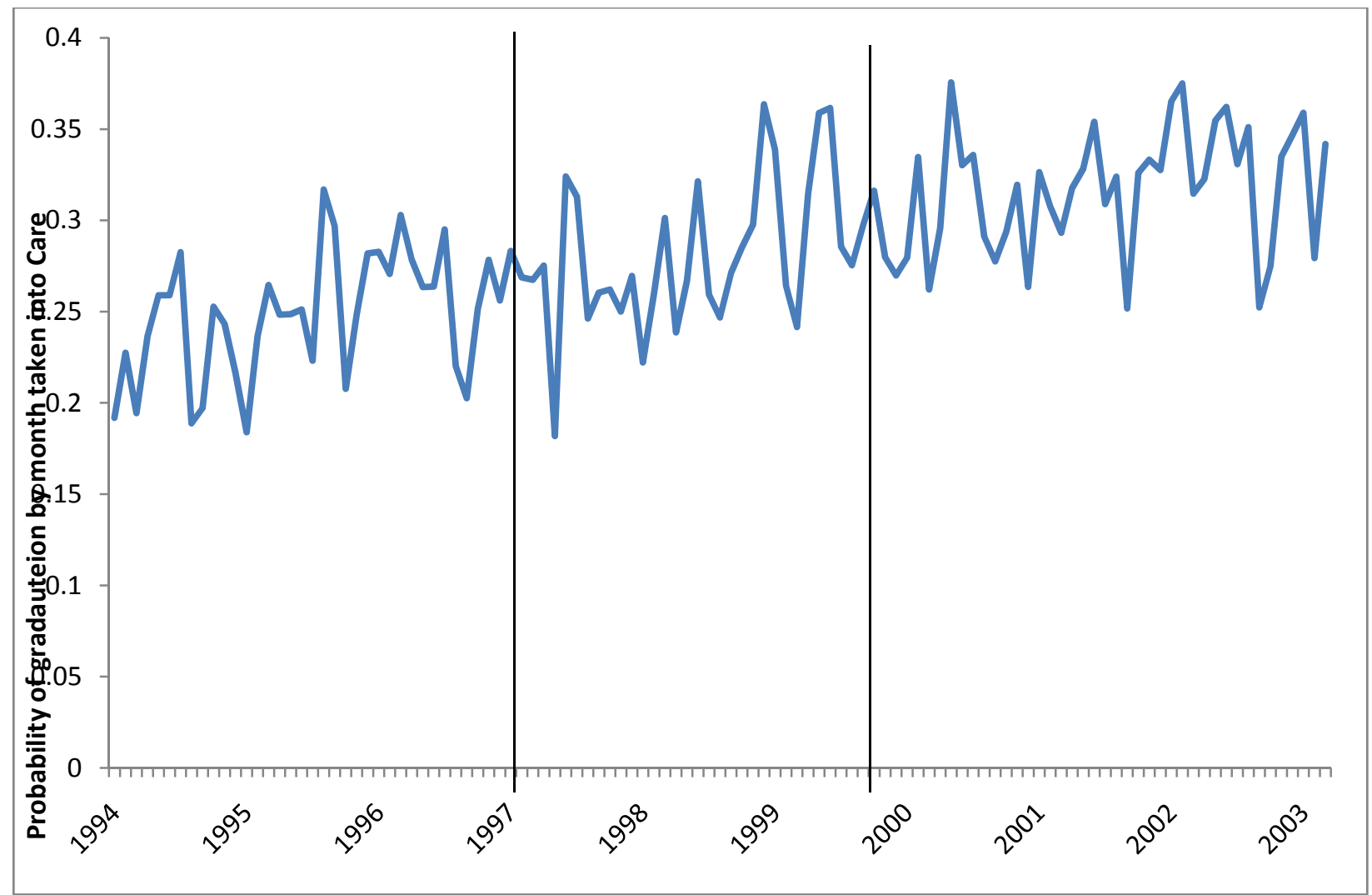

Figure 5 - Probability Graduated from High School at Age 20 by Month Taken into Care 


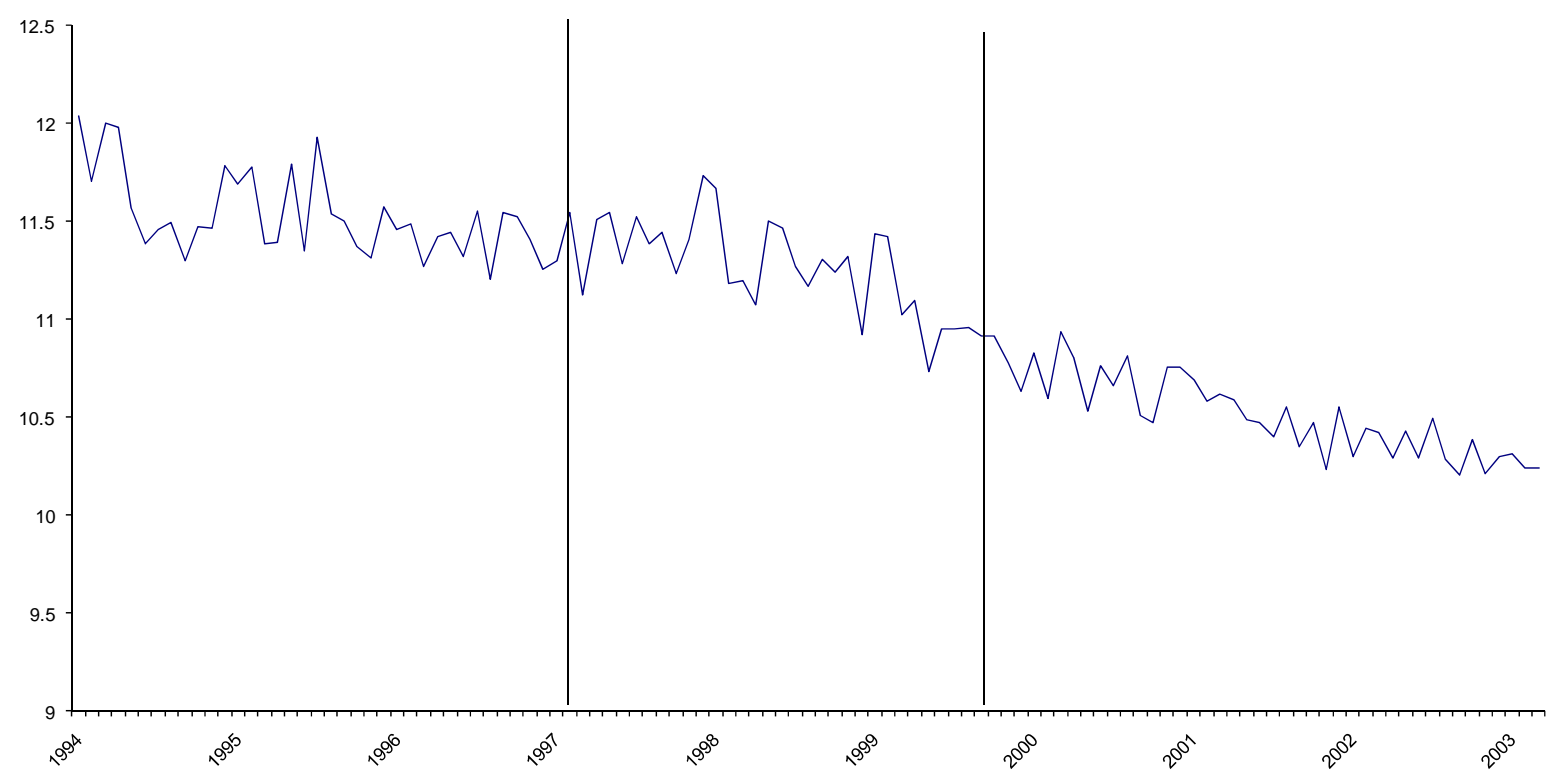

Figure 6 - Percentage on Income Assistance in Year While Age 19 by Month Taken into Care 


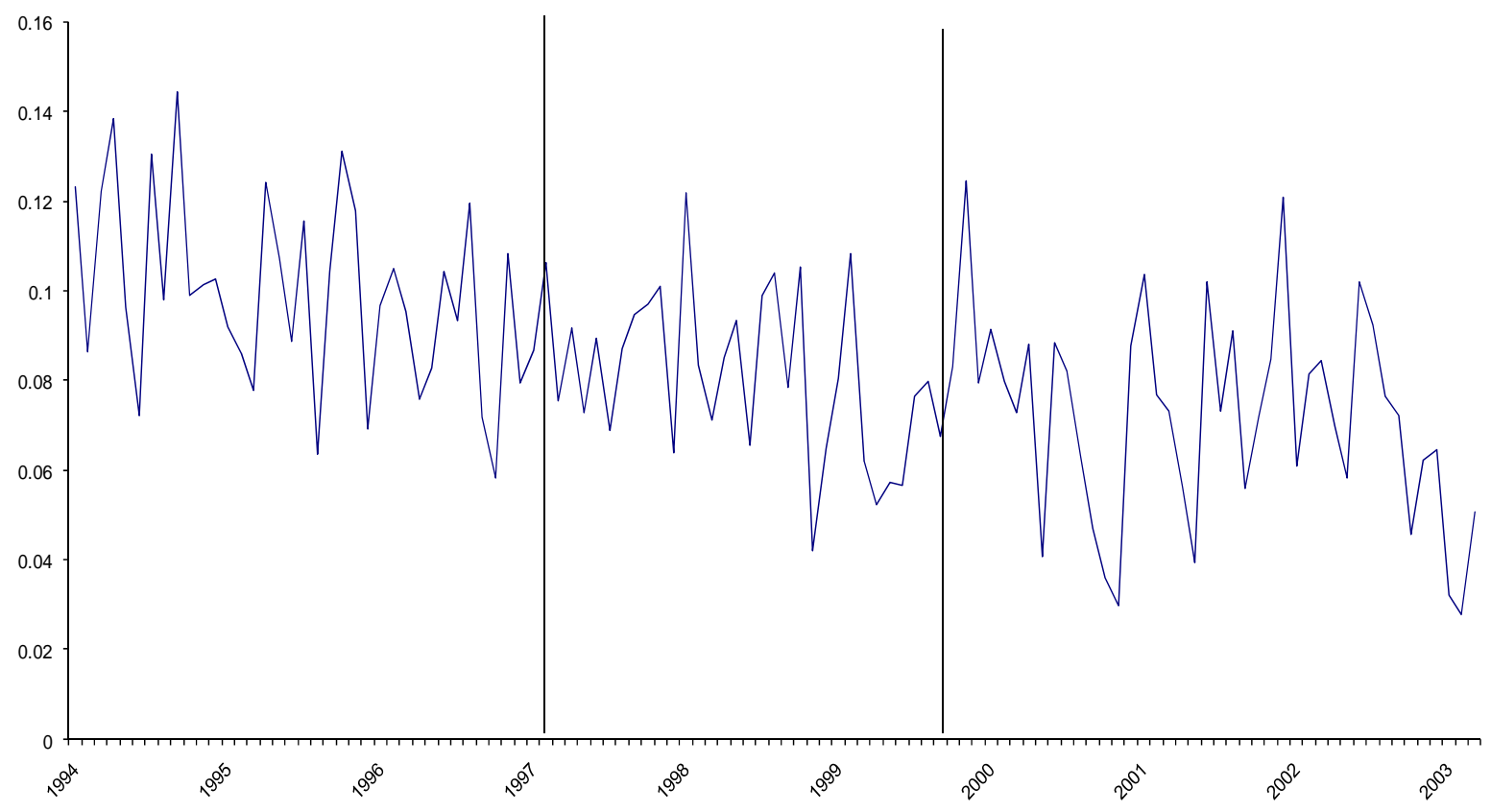

Figure 7 - Percentage Incarcerated in Year When Age 19 by Month Taken into Care 
Table 1 -- Descriptive Statistics

$\begin{array}{llll}\text { Total } & \text { Period } 1 & \text { Period } 2 & \text { Period } 3\end{array}$

Avg Removal Rate

$\begin{array}{rrrr}0.109 & 0.097 & 0.137 & 0.099 \\ (0.312) & (0.296) & (0.344) & (0.299)\end{array}$

Pr(HS grad by age 20)

If removed

$\begin{array}{rrrr}0.123 & 0.110 & 0.115 & 0.143 \\ (0.329) & (0.313) & (0.319) & (0.350) \\ 0.292 & 0.249 & 0.294 & 0.325 \\ (0.455) & (0.433) & (0.456) & (0.468)\end{array}$

Months IA when 19

If removed

If not removed

(4.711)

(4.807)

(4.715)

2.601

2.100

3.112

2.393

(4.192)

(3.855)

$\operatorname{Pr}$ (Convicted when 19)

$(4.355)$

(3.994)

1.068

(2.962)

If removed

$\begin{array}{llll}0.090 & 0.101 & 0.103 & 0.069\end{array}$

$\begin{array}{llll}(0.287) & (0.301) & (0.304) & (0.254)\end{array}$

If not removed

0.038

0.052

0.035

0.028

(0.190)

(0.222)

(0.184)

(0.165)

Frequency

20727

6664

5910

8153

Percent

100

32.15

28.51

39.34

Note: Standard Deviations in parentheses. 
Table 2 - OLS First Stage Regressions: Dependent Variable is InCare (0/1)

\begin{tabular}{|c|c|c|c|c|c|c|c|c|c|c|}
\hline & $(1)$ & $(2)$ & (3) & (4) & (5) & (6) & $(7)$ & (8) & (9) & (10) \\
\hline Period 1 & $\begin{array}{l}0.0377^{*} \\
{[0.022]}\end{array}$ & $\begin{array}{l}0.0328 \\
{[0.022]}\end{array}$ & & & & & $\begin{array}{l}0.0370 * \\
{[0.022]}\end{array}$ & $\begin{array}{l}0.0320 \\
{[0.022]}\end{array}$ & $\begin{array}{l}0.0367 \\
{[0.022]}\end{array}$ & $\begin{array}{l}0.0317 \\
{[0.022]}\end{array}$ \\
\hline Period 2 & $\begin{array}{l}0.0595^{\star * \star} \\
{[0.014]}\end{array}$ & $\begin{array}{l}0.0572^{\star \star \star} \\
{[0.014]}\end{array}$ & & & & & $\begin{array}{l}0.0609 * \star \star \\
{[0.014]}\end{array}$ & $\begin{array}{l}0.0586^{\star \star *} \\
{[0.013]}\end{array}$ & $\begin{array}{l}0.0604^{\star \star \star} \\
{[0.014]}\end{array}$ & $\begin{array}{l}0.0582^{\star \star *} \\
{[0.014]}\end{array}$ \\
\hline Worker FE & & & $\begin{array}{l}0.5207^{\star * *} \\
{[0.066]}\end{array}$ & $\begin{array}{l}0.5171^{\star \star \star} \\
{[0.066]}\end{array}$ & $\begin{array}{l}0.5185^{\star \star \star} \\
{[0.064]}\end{array}$ & $\begin{array}{l}0.5146 * \star \star \\
{[0.064]}\end{array}$ & $\begin{array}{l}0.5223^{* * *} \\
{[0.066]}\end{array}$ & $\begin{array}{l}0.5201^{\star * *} \\
{[0.064]}\end{array}$ & & \\
\hline $\mathrm{P} 1{ }^{\star} \mathrm{Wkr}$ FE & & & & & & & & & $\begin{array}{l}0.4977^{\star \star \star} \\
{[0.129]}\end{array}$ & $\begin{array}{l}0.4864^{\star \star *} \\
{[0.127]}\end{array}$ \\
\hline $\mathrm{P} 2{ }^{*} \mathrm{Wkr} F E$ & & & & & & & & & $\begin{array}{l}0.4768^{\star \star \star} \\
{[0.111]}\end{array}$ & $\begin{array}{l}0.4822^{\star \star \star} \\
{[0.108]}\end{array}$ \\
\hline P3*Wkr FE & & & & & & & & & $\begin{array}{l}0.5756^{\star \star \star} \\
{[0.096]}\end{array}$ & $\begin{array}{l}0.5724^{\star \star *} \\
{[0.093]}\end{array}$ \\
\hline Partial R2 & 0.002 & 0.002 & 0.008 & & 0.008 & & 0.010 & 0.010 & 0.010 & 0.010 \\
\hline $\begin{array}{l}\text { F(inst, 2864) } \\
\text { P-value }\end{array}$ & $\begin{array}{c}16.83 \\
(0.000)\end{array}$ & $\begin{array}{c}17.78 \\
(0.000)\end{array}$ & $\begin{array}{c}61.74 \\
(0.000)\end{array}$ & -- & $\begin{array}{c}64.8 \\
(0.000)\end{array}$ & -- & $\begin{array}{c}32.49 \\
(0.000)\end{array}$ & $\begin{array}{c}34.8 \\
(0.000)\end{array}$ & $\begin{array}{c}20.01 \\
(0.000)\end{array}$ & $\begin{array}{c}21.49 \\
(0.000)\end{array}$ \\
\hline 11 Month Vars & Yes & Yes & Yes & Yes & Yes & Yes & Yes & Yes & Yes & Yes \\
\hline $\begin{array}{l}\text { 3rd order poly } \\
\text { Year Vars } \\
28 \text { background }\end{array}$ & Yes & Yes & Yes & Yes & Yes & Yes & Yes & Yes & Yes & Yes \\
\hline vars & & Yes & & & Yes & Yes & & Yes & & Yes \\
\hline Observations & 20727 & 20727 & 20727 & 20727 & 20727 & 20727 & 20727 & 20727 & 20727 & 20727 \\
\hline R-squared & 0.0062 & 0.0492 & 0.0133 & 0.0122 & 0.0563 & 0.0551 & 0.0144 & 0.0574 & 0.0145 & 0.0574 \\
\hline
\end{tabular}

Heteroscedasticity robust standard errors, clustered on worker-year, in brackets. ${ }^{\star \star *} p<0.01,{ }^{* \star} p<0.05,{ }^{*} p<0.1$

All regressions also include a linear control for age at first contact measured in months.

Anderson canonical correlation, \& Craig-Donald, tests always have p-values of 0.0000 for these regressions, but are not robust to

clustering, so the test statistics are biased toward low p-values and, therefore, they are not presented. 
Table 3 - OLS and IV Results with High School Graduate by Age 20 as the Dependant Variable

\begin{tabular}{|c|c|c|c|c|c|c|c|c|c|c|}
\hline & (1) & (2) & (3) & (4) & (5) & (6) & (7) & (8) & (9) & (10) \\
\hline & OLS & IV & IV & IV & IV & OLS & IV & IV & IV & IV \\
\hline Instruments & & $\mathrm{P} 1, \mathrm{P} 2$ & Wkr FE & $\begin{array}{l}\text { P1, P2, } \\
\text { Wkr FE }\end{array}$ & $\begin{array}{c}\text { P1, P2, } \\
\text { FE1, } \\
\text { FE2, FE3 }\end{array}$ & & $\mathrm{P} 1, \mathrm{P} 2$ & Wkr FE & $\begin{array}{l}\text { P1, P2, } \\
\text { Wkr FE }\end{array}$ & $\begin{array}{c}\text { P1, P2, } \\
\text { FE1, } \\
\text { FE2, FE3 }\end{array}$ \\
\hline InCare & $\begin{array}{c}-0.1301^{\star \star \star} \\
{[0.008]}\end{array}$ & $\begin{array}{c}-0.2744 \\
{[0.204]}\end{array}$ & $\begin{array}{c}-0.1956^{\star} \\
{[0.103]}\end{array}$ & $\begin{array}{c}-0.1884^{\star \star} \\
{[0.090]}\end{array}$ & $\begin{array}{c}-0.1778^{\star \star} \\
{[0.091]}\end{array}$ & $\begin{array}{c}-0.1701^{\star \star \star} \\
{[0.008]}\end{array}$ & $\begin{array}{c}-0.2981 \\
{[0.210]}\end{array}$ & $\begin{array}{c}-0.1893^{*} \\
{[0.105]}\end{array}$ & $\begin{array}{c}-0.2133^{\star \star} \\
{[0.093]}\end{array}$ & $\begin{array}{c}-0.2027^{\star *} \\
{[0.093]}\end{array}$ \\
\hline $\begin{array}{l}\text { Anderson-Rubin } \\
p \text {-value } \text { chi }^{2} \text { (inst) }\end{array}$ & & $\begin{array}{c}3.72 \\
(0.1555)\end{array}$ & $\begin{array}{c}3.59 \\
(0.0582)\end{array}$ & $\begin{array}{c}6.36 \\
(0.0952)\end{array}$ & $\begin{array}{c}8.94 \\
(0.1114)\end{array}$ & & $\begin{array}{c}3.9 \\
(0.1424)\end{array}$ & $\begin{array}{c}3.11 \\
(0.0778)\end{array}$ & $\begin{array}{c}7.14 \\
(0.0675)\end{array}$ & $\begin{array}{c}9.68 \\
(0.0847)\end{array}$ \\
\hline $\begin{array}{l}\text { Sargan-Hansen J } \\
p \text {-value } x^{2} \text { (inst- } 1 \text { ) }\end{array}$ & & $\begin{array}{c}1.801 \\
(0.180)\end{array}$ & & $\begin{array}{c}2.084 \\
(0.353)\end{array}$ & $\begin{array}{c}4.339 \\
(0.362)\end{array}$ & & $\begin{array}{c}1.801 \\
(0.180)\end{array}$ & & $\begin{array}{c}2.063 \\
(0.356)\end{array}$ & $\begin{array}{c}4.303 \\
(0.367)\end{array}$ \\
\hline 3rd order poly & Yes & Yes & & Yes & Yes & Yes & Yes & Yes & Yes & Yes \\
\hline 28 control vars & Yes & Yes & Yes & Yes & Yes & & & & & \\
\hline 11 month vars & Yes & Yes & Yes & Yes & Yes & Yes & Yes & Yes & Yes & Yes \\
\hline Observations & 20727 & 20727 & 20727 & 20727 & 20727 & 20727 & 20727 & 20727 & 20727 & 20727 \\
\hline R-squared & 0.0704 & 0.0607 & 0.0626 & 0.0688 & 0.0693 & 0.0225 & 0.0145 & 0.0223 & 0.0216 & 0.0220 \\
\hline
\end{tabular}


Table 4-OLS and IV Estimates with Income Assistance use while Age 19 as the Dependent Variable

\begin{tabular}{|c|c|c|c|c|c|c|c|c|c|c|}
\hline & (1) & (2) & (3) & (4) & (5) & (6) & (7) & (8) & (9) & (10) \\
\hline & OLS & IV & IV & IV & IV & OLS & IV & IV & IV & IV \\
\hline Instruments & & $\mathrm{P} 1, \mathrm{P} 2$ & Wkr FE & $\begin{array}{l}\text { P1, P2, } \\
\text { Wkr FE }\end{array}$ & $\begin{array}{l}\text { P1, P2, } \\
\text { FE1, } \\
\text { FE2, FE3 }\end{array}$ & & $\mathrm{P} 1, \mathrm{P} 2$ & Wkr FE & $\begin{array}{l}\text { P1, P2, } \\
\text { Wkr FE }\end{array}$ & $\begin{array}{c}\text { P1, P2, } \\
\text { FE1, } \\
\text { FE2, FE3 }\end{array}$ \\
\hline InCare & $\begin{array}{c}1.6100 * * \star \\
{[0.101]}\end{array}$ & $\begin{array}{c}8.8693^{\star * *} \\
{[2.311]}\end{array}$ & $\begin{array}{l}1.4424 \\
{[1.106]}\end{array}$ & $\begin{array}{c}2.3442^{\star \star \star} \\
{[0.902]}\end{array}$ & $\begin{array}{c}2.3328^{\star \star \star} \\
{[0.887]}\end{array}$ & $\begin{array}{c}1.9784^{\star \star \star} \\
{[0.100]}\end{array}$ & $\begin{array}{c}9.1839 * \star \star \\
{[2.395]}\end{array}$ & $\begin{array}{l}1.0805 \\
{[1.058]}\end{array}$ & $\begin{array}{c}2.7933^{\star \star \star} \\
{[0.940]}\end{array}$ & $\begin{array}{c}2.7689 \star \star \star \star \\
{[0.923]}\end{array}$ \\
\hline $\begin{array}{l}\text { Anderson-Rubin } \\
p \text {-value chi }{ }^{2} \text { (inst) }\end{array}$ & & $\begin{array}{c}20.61 \\
(0.0000)\end{array}$ & $\begin{array}{c}1.66 \\
(0.1981)\end{array}$ & $\begin{array}{c}20.94 \\
(0.0001)\end{array}$ & $\begin{array}{c}21.04 \\
(0.0008)\end{array}$ & & $\begin{array}{c}19.84 \\
(0.0000)\end{array}$ & $\begin{array}{c}0.99 \\
(0.3194)\end{array}$ & $\begin{array}{c}20.61 \\
(0.0001)\end{array}$ & $\begin{array}{c}20.63 \\
(0.0010)\end{array}$ \\
\hline $\begin{array}{l}\text { Sargan-Hansen } J \\
\left.p \text {-value } x^{2} \text { (inst- } 1\right)\end{array}$ & & $\begin{array}{c}0.001 \\
(0.9715)\end{array}$ & & $\begin{array}{c}14.071 \\
(0.0009)\end{array}$ & $\begin{array}{c}14.672 \\
(0.0054)\end{array}$ & & $\begin{array}{c}0.054 \\
(0.8162)\end{array}$ & & $\begin{array}{c}12.533 \\
(0.0019)\end{array}$ & $\begin{array}{c}13.376 \\
(0.0096)\end{array}$ \\
\hline 3rd order poly & Yes & Yes & & Yes & Yes & Yes & Yes & Yes & Yes & Yes \\
\hline 28 control vars & Yes & Yes & Yes & Yes & Yes & & & & & \\
\hline 11 month vars & Yes & Yes & Yes & Yes & Yes & Yes & Yes & Yes & Yes & Yes \\
\hline Observations & 20727 & 20727 & 20727 & 20727 & 20727 & 20727 & 20727 & 20727 & 20727 & 20727 \\
\hline R-squared & 0.1653 & 0.1390 & 0.1110 & 0.1622 & 0.1623 & 0.0899 & 0.2235 & 0.0850 & 0.0859 & 0.0861 \\
\hline
\end{tabular}


Table 5 - OLS and IV Estimates with Incarceration while Age 19 as the Dependent Variable

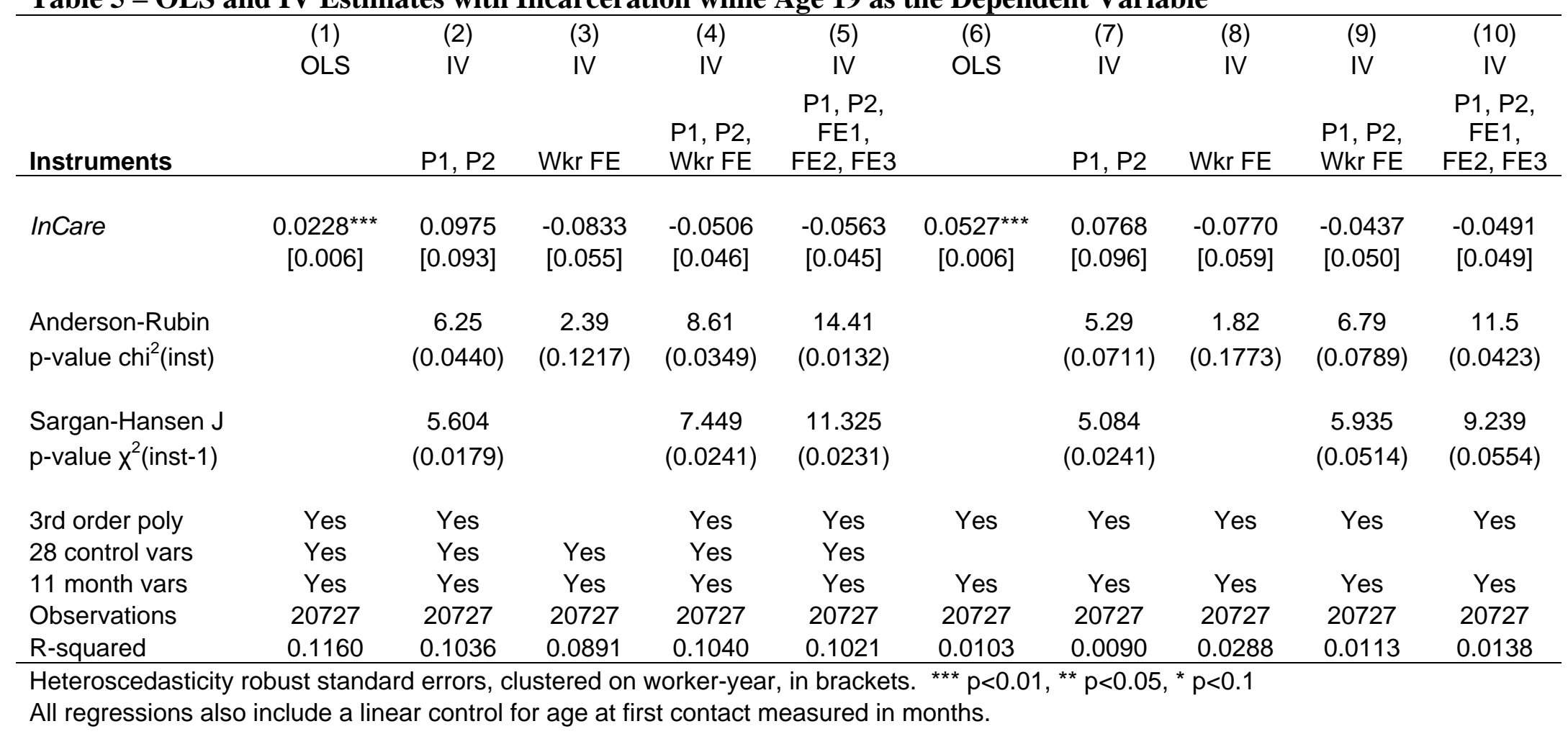


Appendix Table 1 - Descriptive Statistics by Period

\begin{tabular}{|c|c|c|c|}
\hline \multicolumn{4}{|c|}{ Period 1} \\
\hline \multirow[t]{2}{*}{ Substance Abuse } & 0.063 & 0.073 & 0.085 \\
\hline & $(0.598)$ & $(0.548)$ & $(0.803)$ \\
\hline \multirow[t]{2}{*}{ Psychoses } & 0.083 & 0.079 & 0.130 \\
\hline & $(1.190)$ & (1.139) & $(1.550)$ \\
\hline \multirow[t]{2}{*}{ Disturb. conduct } & 0.079 & 0.093 & 0.103 \\
\hline & $(0.701)$ & $(0.805)$ & $(0.687)$ \\
\hline \multirow[t]{2}{*}{ Adolescent problem } & 0.069 & 0.086 & 0.086 \\
\hline & $(0.710)$ & $(1.069)$ & $(0.972)$ \\
\hline \multirow[t]{2}{*}{ Hyperactivity } & 0.090 & 0.144 & 0.165 \\
\hline & $(0.910)$ & $(0.986)$ & $(1.122)$ \\
\hline \multirow[t]{2}{*}{ Devel. Delay } & 0.021 & 0.014 & 0.015 \\
\hline & $(0.448)$ & $(0.332)$ & $(0.210)$ \\
\hline \multirow[t]{2}{*}{ Neuroses } & 0.414 & 0.430 & 0.494 \\
\hline & $(2.315)$ & $(1.975)$ & $(2.295)$ \\
\hline \multirow[t]{2}{*}{ STD } & 0.005 & 0.005 & 0.004 \\
\hline & $(0.097)$ & $(0.087)$ & $(0.076)$ \\
\hline \multirow[t]{2}{*}{ Maltreatment } & 0.022 & 0.014 & 0.018 \\
\hline & (0.199) & $(0.127)$ & $(0.223)$ \\
\hline \multirow[t]{2}{*}{ Health Other } & 8.341 & 7.757 & 7.274 \\
\hline & $(9.247)$ & $(8.841)$ & $(7.858)$ \\
\hline \multicolumn{4}{|l|}{ Corrections } \\
\hline \multirow[t]{2}{*}{ Incarceration } & 0.042 & 0.038 & 0.026 \\
\hline & $(0.200)$ & $(0.190)$ & $(0.158)$ \\
\hline \multirow[t]{2}{*}{ Violent } & 0.017 & 0.023 & 0.016 \\
\hline & $(0.130)$ & $(0.148)$ & $(0.124)$ \\
\hline \multirow[t]{2}{*}{ Contact } & 0.188 & 0.164 & 0.129 \\
\hline & $(0.391)$ & $(0.370)$ & $(0.336)$ \\
\hline \multicolumn{4}{|l|}{ Income Assistance } \\
\hline \multirow[t]{2}{*}{ CIHR3 } & 0.072 & 0.078 & 0.072 \\
\hline & $(0.425)$ & $(0.449)$ & $(0.435)$ \\
\hline \multirow[t]{2}{*}{ CIHR24 } & 0.379 & 0.437 & 0.434 \\
\hline & $(2.219)$ & $(2.544)$ & $(2.584)$ \\
\hline \multirow[t]{2}{*}{ IA3 } & 0.776 & 0.728 & 0.656 \\
\hline & $(1.250)$ & $(1.220)$ & $(1.191)$ \\
\hline \multirow[t]{2}{*}{ IA24 } & 5.052 & 5.560 & 4.863 \\
\hline & $(8.030)$ & $(8.273)$ & $(8.020)$ \\
\hline \multicolumn{4}{|c|}{ Demographic (Language spoken at home) } \\
\hline \multirow[t]{2}{*}{ Aboriginal } & 0.164 & 0.201 & 0.233 \\
\hline & $(0.370)$ & $(0.401)$ & $(0.423)$ \\
\hline \multirow[t]{2}{*}{ Chinese } & 0.010 & 0.015 & 0.013 \\
\hline & $(0.101)$ & $(0.123)$ & $(0.114)$ \\
\hline \multirow[t]{2}{*}{ Punjabi } & 0.013 & 0.012 & 0.012 \\
\hline & $(0.112)$ & $(0.110)$ & $(0.110)$ \\
\hline Vietnamese & 0.006 & 0.012 & 0.014 \\
\hline & $(0.080)$ & $(0.108)$ & $(0.118)$ \\
\hline
\end{tabular}




$\begin{array}{lccc}\text { Spanish } & 0.012 & 0.014 & 0.013 \\ & (0.110) & (0.117) & (0.111) \\ \text { Tagalog } & 0.003 & 0.007 & 0.008 \\ & (0.055) & (0.083) & (0.092) \\ \text { Hindi } & 0.005 & 0.006 & 0.007 \\ & (0.068) & (0.076) & (0.086) \\ \text { Persian } & 0.003 & 0.004 & 0.005 \\ & (0.057) & (0.061) & (0.073) \\ \text { French } & 0.005 & 0.009 & 0.008 \\ & (0.072) & (0.093) & (0.091) \\ \text { Portuguese } & 0.003 & 0.006 & 0.010 \\ & (0.050) & (0.077) & (0.097) \\ \text { Other, Non English } & 0.026 & 0.043 & 0.046 \\ & (0.158) & (0.203) & (0.210)\end{array}$

Notes: Each health variable is derived from the ICD9 codes on physician billing records and counts the number of days in which the subject had one of the named diagnoses. Where these classifications overlap, the larger group reports the residual. The 3 variables from Corrections indicate: any contact, incarceration or incarceration for a violent offence in the year prior to contact with child protection. Of the 4 variables reflecting income assistance, 2 variables measure receipt of benefits through the child in the home of a relative program (CIHR), and there are 2 indicating receipt of income Assistance (IA) benefits through their family. In each case the first counts the number of months in the three months prior to contact, and the second counts the number of months in the 22 months prior to that. One variable is an indicator for self-declared aboriginal status in the education system and 10 dummy variables indicate self-declared language spoken at home. 